\title{
Fit for purpose
}

[ B O O K R E VIE W ]

Smith, Cora, Lobban, Glenys \& O'Loughlin, Michael (eds) (2013) Psychodynamic psychotherapy in South Africa. Johannesburg: Wits University Press. ISBN 978-1-86814-603-1 pbk. Pages xi + 292

\section{Sharon M Auld}

Durban

sharon@auldfamily.com

News headlines today scream of abuse, violence, intolerance, inequality, and moral bankruptcy. In South Africa, our violent history of apartheid and post-apartheid strife - including the recent xenophobic attacks that have gripped KwaZulu-Natal - highlight issues of physical and emotional anguish, fractured and displaced families, acting out around difference, and economic suffering that not only inform the backdrop to, but are also very palpable within the psychoanalytic space. Emerging from this turbulent context Psychodynamic psychotherapy in South Africa questions the usefulness of psychoanalytically orientated theory and practice in post-apartheid South Africa.

Overall this is a tough book. It has to be. It hits hard from the get go, dealing with often complex, dense, and multi-layered concepts and arguments. Heavy weight theories such as postmodernism, psychoanalysis, postcolonialism, and social identity are grappled with from chapter one. Experienced clinicians, teachers, and researchers comprising Sally Swartz, Yvette Esprey, Glenys Lobban, Cora Smith, Gill Eagle, Gavin Ivey, Tina Sideris, Giada Del Fabbro, Vanessa Hemp, and Michael O'Loughlin each contribute a chapter. Throughout the book there is a persistent analysis of the relevance of psychoanalysis to the South African context, where, 
added to post-apartheid discord, there are also international issues such as restrictions in terms of resources, time, and trained staff. Such a tenacious analysis of the relevance of psychoanalysis is deemed necessary if psychoanalytic orientated theory and practice are to have any purchase in the future of the country.

The book's ten chapters are grouped into three sections, enabling ease of pertinent reading. Section one explores issues of race, identity, disavowal, and otherness viewed within an intersubjective theoretical framework. Section two looks at psychodynamic perspectives of trauma, the impact of violence on attachment, and the psychotherapeutic dilemmas these raise for therapists. Section three looks at current social issues relating to clinical practice in South Africa such as psychotherapy and traditional healing, the politics and psychodynamics of gendered violence, group therapy with HIV orphans, the proliferation of serial murder, and the potential for reparative psychotherapy in South Africa.

While all chapters in this book prove worthy, I will focus particularly on those that I found most notable. Sally Swartz's Naming \& otherness: South African intersubjective psychoanalytic psychotherapy and the negotiation of racialised histories (chapter 1) explores the "us-them divide" which undermines human connection. She discusses how, psychotherapeutically speaking, sharing experience through meaningful words sets up a sense of understanding that is potentially transformative. However, this process tends to occur where there is a sense of commonality. In reality, many discourses have the effect of marking difference, of "othering". This has damaging effects: it is an act of interpellation that changes an individual into simply an agent of a group. The challenge is to make a co-constructed intersubjective space (an analytic space) in which designation is an invitation to play, and where difference in identity is not an end-point but a chance for further exploration - towards a shared humanity. To aid in this endeavour, Swartz suggests several points to guide the therapist. Firstly, the more the therapist is aware of his or her own gender, race, and history, the less likely he or she is to dissociate from their own otherness and project it onto the patient. Secondly, naming might be less traumatic if the therapist comes to terms with the ways $s /$ he has been named. Thirdly, the therapist should strive to be playful and curious in order to support the potential for the development of a transformative space. Fourthly, the therapist should bear in mind that through play identity can be revealed with dignity, not shame or anger. Ultimately, the hope is for psychoanalytically orientated practice to be a place for understanding otherness which can reach across the divide.

Raising the colour bar: Exploring issues of race, racism and racialized identities in the South African therapeutic context (chapter 2) by Yvette Esprey, highlights how there has been an avoidance of psychoanalytical discussion around identity - race, gender, and sexual orientation - given the domination of patriarchal, heterosexual, and white discourses in 
South Africa. This chapter is about race and the space it takes up in the therapy room. In this discussion race is seen as an aspect of identity which is a dynamic of both the patient and therapist in the therapeutic space. Continuing this theme, Subjectivity and identity in South Africa today (chapter 3), by Glenys Lobban, explores how race shapes subjectivity and identity. In South Africa psychoanalysis has been concerned with therapeutic application, and as a result psychoanalysis in this country has been more focused on personal insight than on social analysis. South African psychoanalytic psychotherapy has tended to view the self as unchanging across context, rather than focusing on how culture shapes subjectivity. However, Lobban explains that the individual cannot be separated from the social context, and that both individual and social factors are involved in the development of subjectivity and identity. Lobban highlights how, under apartheid, identity was not just an individual choice, how racial identity was externally imposed upon South Africans.

Psychotherapy and disrupted attachment in the aftermath (chapter 4) by Cora Smith, looks at the local difficulties experienced undertaking psychotherapeutic work in the post-apartheid public sector, as well as international issues such as theoretical diversity and economic pressure to develop short-term therapeutic intervention. Taking a postmodern stance she sees knowledge as contextual. To elaborate let me draw on Denzin (1989: 81) who explains that "... stories move outward from the selves of the person and inward to the groups that give them meaning and structure". Denzin (1989: 10) quotes Marx in the observation that men and women "make their own history, but not ... under conditions they have chosen for themselves; rather on terms immediately existing, given and handed down to them". Therefore, we are not able to escape our social and historical context. As a result Smith believes psychoanalytic concepts and interventions are best understood within the linguistic, theoretical, and ideological bases in which they are rooted. Developing from this perspective, and given the relational nature of psychoanalytical theories, Smith believes that there is potential to question the socially constructed dimensions - encompassing race, class, gender, culture, ethnicity, and sexual orientation - of the analytic dyad.

Several local developments are the catalysts for Gavin Ivey's chapter (6), Unconscious meaning and magic: Comparing psychoanalysis and African indigenous healing. Amongst these is the legal recognition that traditional healers have joined other health care providers as part of South Africa's official healthcare system. Added to this development is the year of post-qualification community service required for professional registration as a clinical psychologist. Ivey believes that reflective comparison between psychoanalysis and indigenous healing can prove useful in formulating formal co-operation between these two forms of symbolic healing in 
the future. Through undertaking such a comparison Ivey delves into an exploration of the sort of place psychoanalysis can negotiate for itself through dialogue with African cultural realities.

Some psychoanalytic reflections on a project working with HIV orphans and their caregivers (chapter 9)by Vanessa Hemp draws on work she undertook to help children psychologically process their grief, and deal with their psychic pain, during a period of dogmatic denial of AIDS by the South African health service. Hemp explores the value of engaging in psychodynamic thinking within community work and discusses how it provides a way of dealing with countertransference feelings and the threat of burnout.

Finally, Reclaiming genealogy, memory and history: The psychodynamic potential for reparative therapy in contemporary South Africa (chapter 10) by Michael O'Loughlin explores our nation's urgency to forget its appalling past and look to a new future - perhaps as highlighted in the removal of colonial statues from prominent positions and the altering of street names. He suggests that forced amnesia runs the risk of creating a version of history that leaves some stories untold, severs people from their socio-historical and ancestral roots, and leaves skeletons lying in wait in the nation's closet. He notes that, psychoanalytically speaking, skeletons from the past inevitably return to haunt us. O'Loughlin discusses how we rather need to retell old stories in new ways. This may enable new possibilities for expressing our identities as individuals, groups, and nations. As a result we could mourn our pasts and rise above the parts of our pasts that prevent us from imagining how to live our lives otherwise.

This refreshing and interesting book certainly opened up a space for me to ponder the legacy of apartheid in my therapeutic practice. It promotes self-reflexivity around the socio-historical context of both therapist and patient. In a nutshell, this book is fit for purpose. It brings forward a new kind of social articulation of psychoanalytic theory and practice that is relevant to this country's unique problems. It is a relevant book which would prove a useful addition to any bookshelf. It would also be invaluable as a core text for post-graduate students of psychology.

\section{Reference}

Denzin, N K (1989) Interpretive biography. London: Sage. 